\title{
On the Structure of Shallow Temperature Inversions*
}

\author{
Yutaka NAGATA**
}

\begin{abstract}
The structure of shallow temperature inversions are studied by using the data from several series of BT observations made at the comparatively small intervals.

Temperature inversion layers usually occur in the sea where the temperature structure is complicated and the isotherms are rugged. Strong inversions can be found near the place where the isotherms are raised and the upward convective motion seems to be existing. Inversion layers are seldom found south of the Kuroshio front.

The horizontal scale of the "small scale" temperature inversion layer is of order of 10 nautical miles. In order to know the structure of the inversion layer, we must select the spatial interval of the observation shorter than 3 nautical miles even in the case of relatively large inversion layer. The shape of the inversion layer seems to change considerably whithin a day. So, it is desirable to select the temporal interval of the observation to be of order of an hour.
\end{abstract}

\section{Introduction}

Temperature inversion layers are often seen in BT traces. Especially, BT traces taken in the mixing zone between the Kuroshio and Oyashio almost always show the zig-zag shape. Sometimes, more than 8 inversion layers are found in a BT trace. Usually, we cannot find any spatial correlation in this region between the inversions observed some 30 nautical miles apart. Large scale current pattern such as the Kuroshio system does not seem to be affected by the existence of such small scale temperature inversions. We refer to the inversions of this type as "small scale" inversions. On the other hand, BT records taken in the sea near the Kuril Island usually indicate the existence of a thick inversion layer, the thickness of which exceeds sometimes $100 \mathrm{~m}$, and this inversion layer can be traced at a distance over several hundred miles. The inversion layer of this type may be referred to as a "large scale" inversion. The stable "large scale" temperature inversion usually indicates the existence of different water masses in layers, and colder but less saline water mass is overlying warmer but more saline water mass and the density structure is stable.

In this paper, we are not concerned with this

* Received June 22, 1967

** Geophysical Institute, University of Tokyo type of "large scale" inversion. The "small scale" inversion has important meanings in physical oceanography as it may show a certain phase of the turbulent mixing phenomena. Although the gross features of small scale inversions were studied by many oceanographers (KAWAI, 1955; KURODA, 1959 and 1960; RODEN, 1964 and NAGATA, 1967), the detailed structure has not been studied up to now, because the ordinary spatial interval of the BT observations is too sparse to study the fine structure. Here, we analyse the data from several series of BT observations which were made at the comparatively small intervals. As the "small scale" inversion layers exhibit very complicated and changeable character, specifically designed observations must be needed in order to know their detailed structures. The main purpose of this paper is to obtain some idea about spatial and temporal scales of the "small scale" inversions as a guide for the future planning of observations.

\section{The temperature inversion off Oshima Island in March 1964}

The prominent temperature inversion layer was found off Oshima Island on the way of the test voyage of the Tansei-maru of the Ocean Research Institute, University of Tokyo, and successive temperature measurements were 
made by using BT in order to clarify the structure of this inversion layer*. Unfortunately, as the weather condition was getting bad, we observed temperature field only in a section along the meridian of $139^{\circ} 40^{\prime} \mathrm{E}$ from north to south. The times of each BT measurement are listed in Table 1. The series of observations was terminated at $23 \mathrm{~h} 18 \mathrm{~m}$ and the course of the ship turned to the north. St. 33 was taken on the way back, near the location of St. 31 . The obtained BT traces are shown in Fig. 1. Fairly good correspondence can be seen between every successive BT traces. The cross-section of the temperature field is constructed from these traces as shown in Fig. 2. In this figure, the positions of the temperature inversion layers

* This observation is carried out by Prof. T. TERAMOTO.
Table 1. Times of BT observations off Oshima Island.

\begin{tabular}{|c|c|c|c|c|}
\hline Station No. & & Time & & \\
\hline 21 & $20 \mathrm{~h}$ & $05 \mathrm{~m}$ & March & 14 \\
\hline 22 & $20 \mathrm{~h}$ & $34 \mathrm{~m}$, & & \\
\hline 23 & $21 \mathrm{~h}$ & $09 \mathrm{~m}$, & & \\
\hline 24 & $21 \mathrm{~h}$ & $19 \mathrm{~m}$, & & \\
\hline 25 & $21 \mathrm{~h}$ & $25 \mathrm{~m}$, & & \\
\hline 26 & $21 \mathrm{~h}$ & $30 \mathrm{~m}$, & & \\
\hline 27 & $21 \mathrm{~h}$ & $36 \mathrm{~m}$, & & \\
\hline 28 & $21 \mathrm{~h}$ & $41 \mathrm{~m}$, & & \\
\hline 29 . & $21 \mathrm{~h}$ & $47 \mathrm{~m}$, & & \\
\hline 30 & $21 \mathrm{~h}$ & $53 \mathrm{~m}$, & & \\
\hline 31 & $22 \mathrm{~h}$ & $34 \mathrm{~m}$ & & \\
\hline 32 & $23 \mathrm{~h}$ & $04 \mathrm{~m}$ & & \\
\hline 33 & $00 \mathrm{~h}$ & $04 \mathrm{~m}$ & March & 15 \\
\hline
\end{tabular}
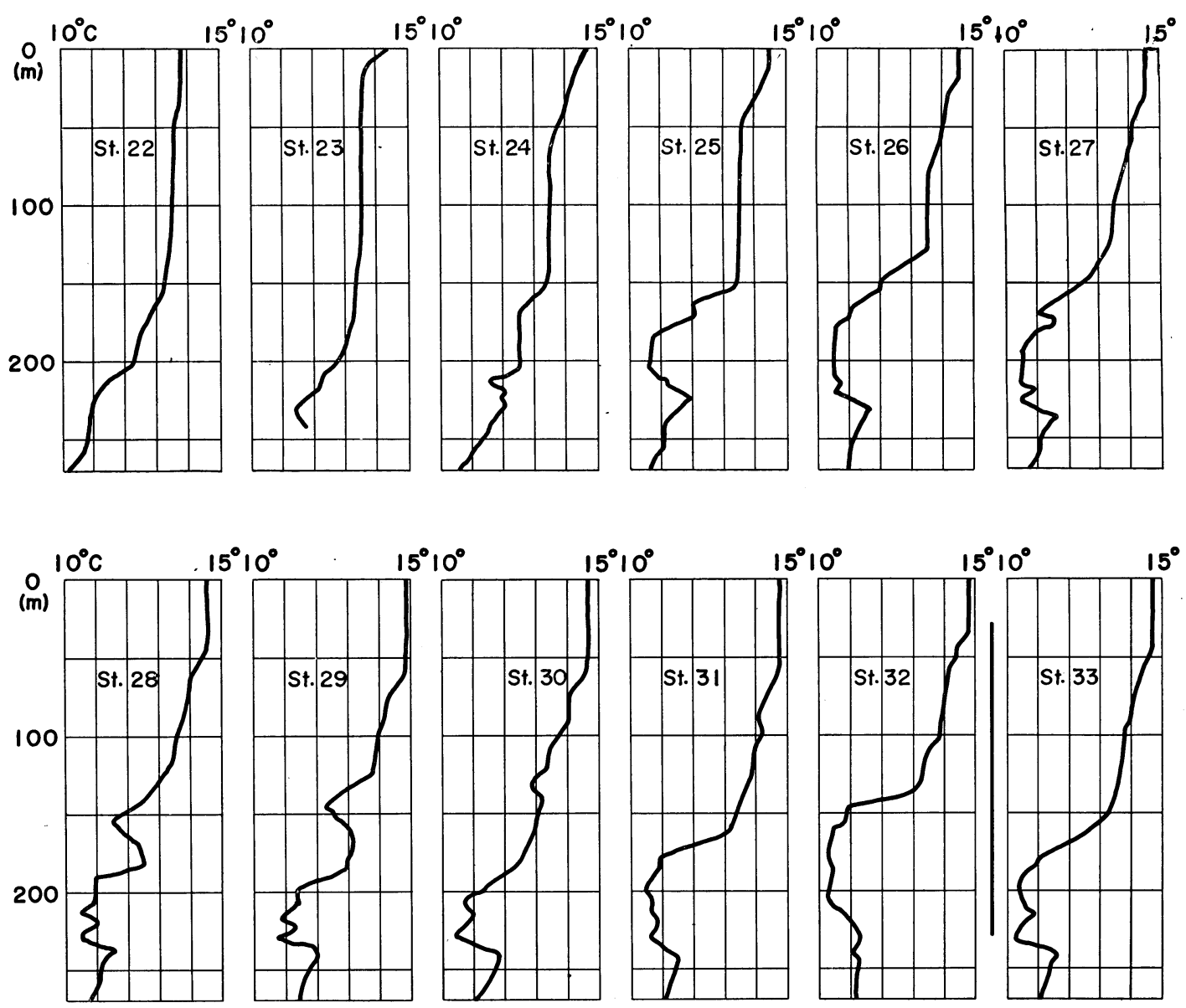

Fig. 1. The temperature inversion layers observed off Oshima Island on March 14, 1964. 


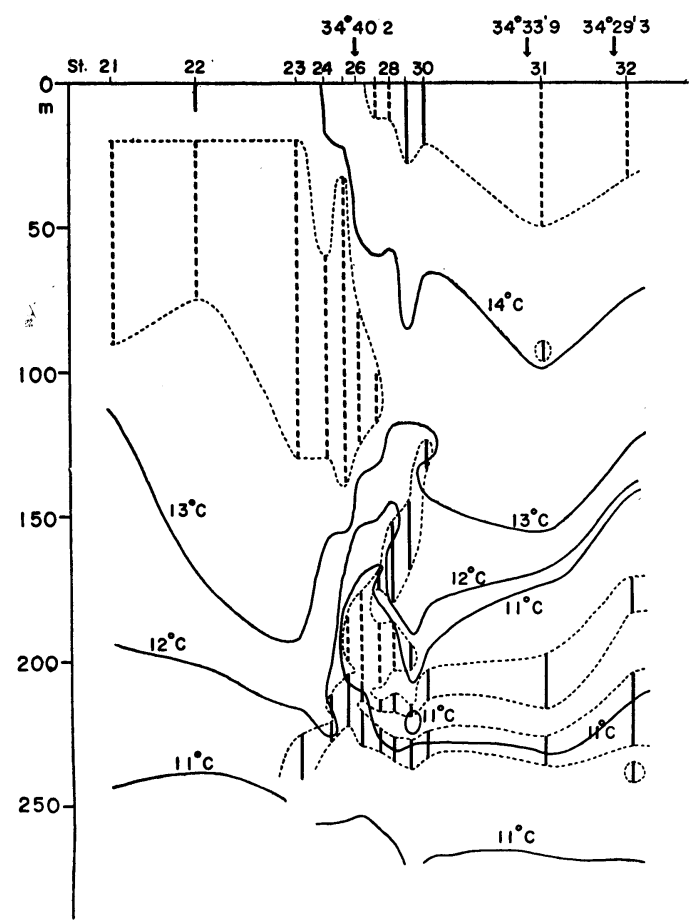

Fig. 2. The cross-section of temperature field and the position of temperature inversion layers (vertical solid line) and homogeneous temperature layers (vertical dashed line). Thin dashed line indicates the deduced correspondence of the successive inversion layers and homogeneous layers.

are shown by vertical solid lines and those of the homogeneous temperature layers by vertical dashed lines. Thin dotted lines indicate the correspondence of the successive inversion layers and homogeneous layers. The observation time is taken in abscissa. The position of the ship was determined three times during the observation and is shown at the upper margin of Fig. 2. Ship speed was 4 knots from St. 24 to St. 30 and from 8 to 10 knots otherwise. G.E.K. measurement was done between Sts. 21 and 22,22 and 23 , and 30 and 31 . The surface current speed was a little less than 1 knot and the direction was from $\mathrm{N}$ to NNE. In Fig. $3 \mathrm{~b}$ through $3 \mathrm{~b}$, temperature fields of this region is shown from "State of the Adjacent Seas of Nippon, Feb.-Mar. 1964", Hydrographic Division, Marine Safety Agency. The position of our observation line is also shown in Fig. 3 by vertical straight line. As seen in Fig. 3,
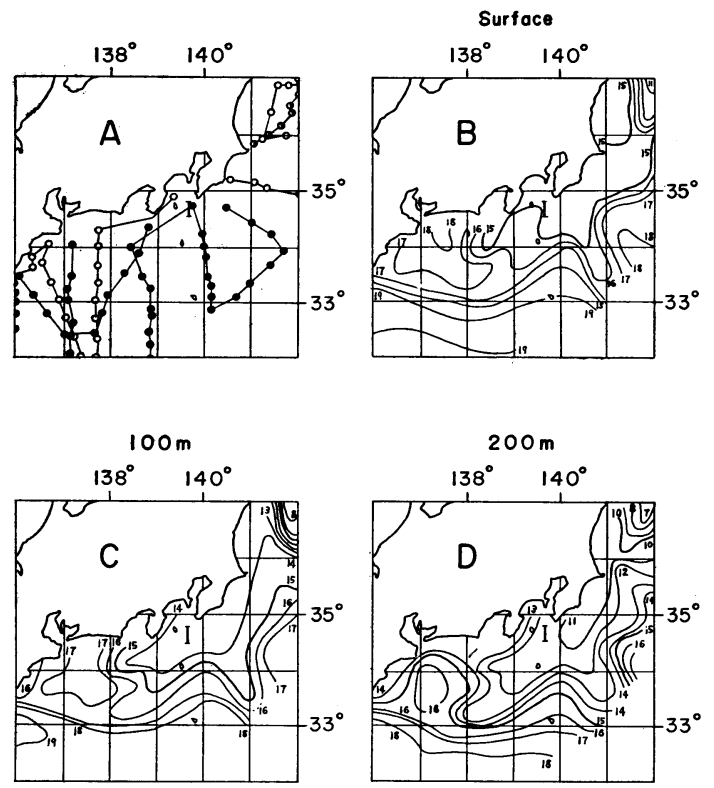

Fig. 3. Sea state of the observed region. A : Locations of base observations, B : isotherms at sea surface, $\mathrm{C}$ : isotherms at the depth of $100 \mathrm{~m}$, and D: isotherms at the depth of $200 \mathrm{~m}$. The location of our observation is shown by vertical straight line in each fig ure

our observation line was located north of the Kuroshio and in the cold water region which was spreading southwest from off Boso peninsula. The inversion layer might be generated at the front of the cold water mass.

The vertical temperature profile changes gradually from station to station. The temperature profile has a minimum at St. 26 , two minima at St. 27 , and three minima at St. 28 through St. 31. The shallowest inversion layer decreases its depth from St. 28 to St. 31 and disappears at St. 32. This inversion layer cannot be seen in the BT trace at St. 33 which was taken on the way back near St. 31 . While, two lower inversion layers can be traced from St. 26 to St. 32 and seen also at St. 33. The isotherms of $12^{\circ} \mathrm{C}$ and $13^{\circ} \mathrm{C}$ in Fig. 2 are raised more than $50 \mathrm{~m}$ at the position where the separation of the inversion happens. This suggests that the temparary convective motion plays important role in the separation of the temperature inversions.

Now let us suppose that the temperature 
profile were obtained only at St. 29. Then it would be hard to speculate that the upper inversion is related to the lower inversions. Also, if we observed the temperature profiles only at St. 25 and St. 29, it would be difficult to imagine the relation between two $\mathrm{BT}$ traces. The horizontal scale of the hump of the $12^{\circ} \mathrm{C}$ and $13^{\circ} \mathrm{C}$ isotherms is about 10 nautical miles. So the related shallowest inversion has the scale less than 10 nautical miles. The horizontal scale of lower inversion layers cannot be estimated as the observation was not extended to the south of St. 32. However, the existence of cold water mass to the south of these observation points is not plausible, so that the horizontal scale of the lower inversions seems not much larger than 20 nautical miles. The detailed shape of the lower inversion layers varys considerably within the observed 20 nautical miles, and this result is consistent with the fact that usually we cannot find any correlation between inversions observed at the interval of 30 nautical miles. Therefore, it seems reasonable to assume the horizontal scale of the small scale inversions to be of order of 10 nautical miles in the planning of the future observation.

The Tansei-maru occupied this observation line also on March 13. BT traces taken in that time also show the existence of inversion layers. The temperature inversions on March 13 appeared at the depths from 160 to $250 \mathrm{~m}$, with temperature differences less than $1^{\circ} \mathrm{C}$ and their thickness less than $20 \mathrm{~m}$. The relation between the inversions observed on March 13 and March 14 was not clear, suggesting the rapid change of the detailed structure of the inversion layers. However, it is certain that the sea state favorable for the generation or the maintenance of inversion layer persisted more than two days.

\section{The temperature inversions near Knroshio front in June 1957}

The multiple ship current measurement was carried out from June to July 1957 in the sea to the east of Japan as one of the oceanographic projects in the IGY period [1957 1958

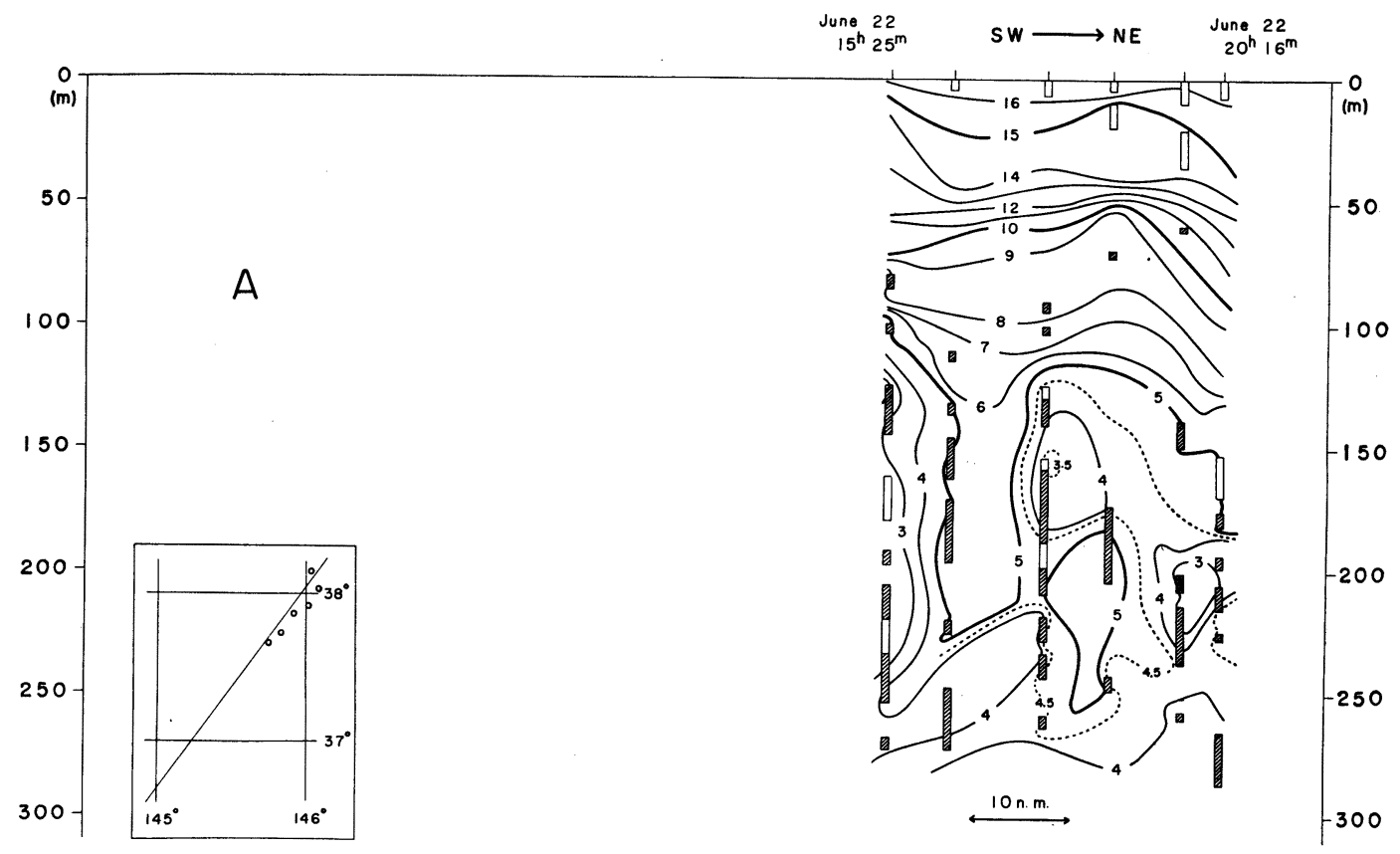

Fig. 4a. Temperature cross-section across the Kuroshio. Shaded rectangles indicate the positions of the temperature inversion layers and white rectangles indicate those of the homogeneous temperature layers. Locations of BT observations and the reference line are also shown. 


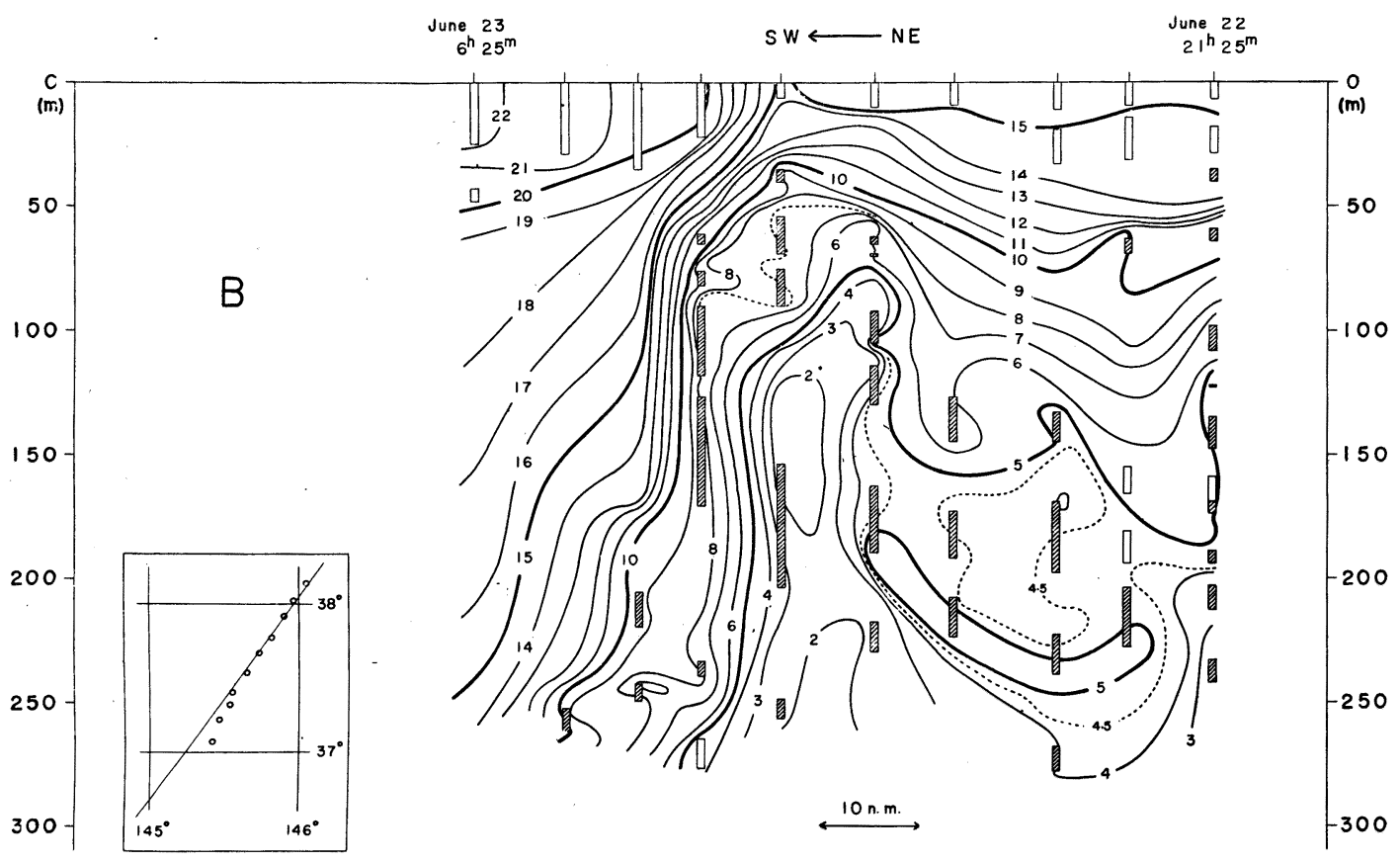

Fig. 4b. Temperature cross-section across the Kuroshio front.

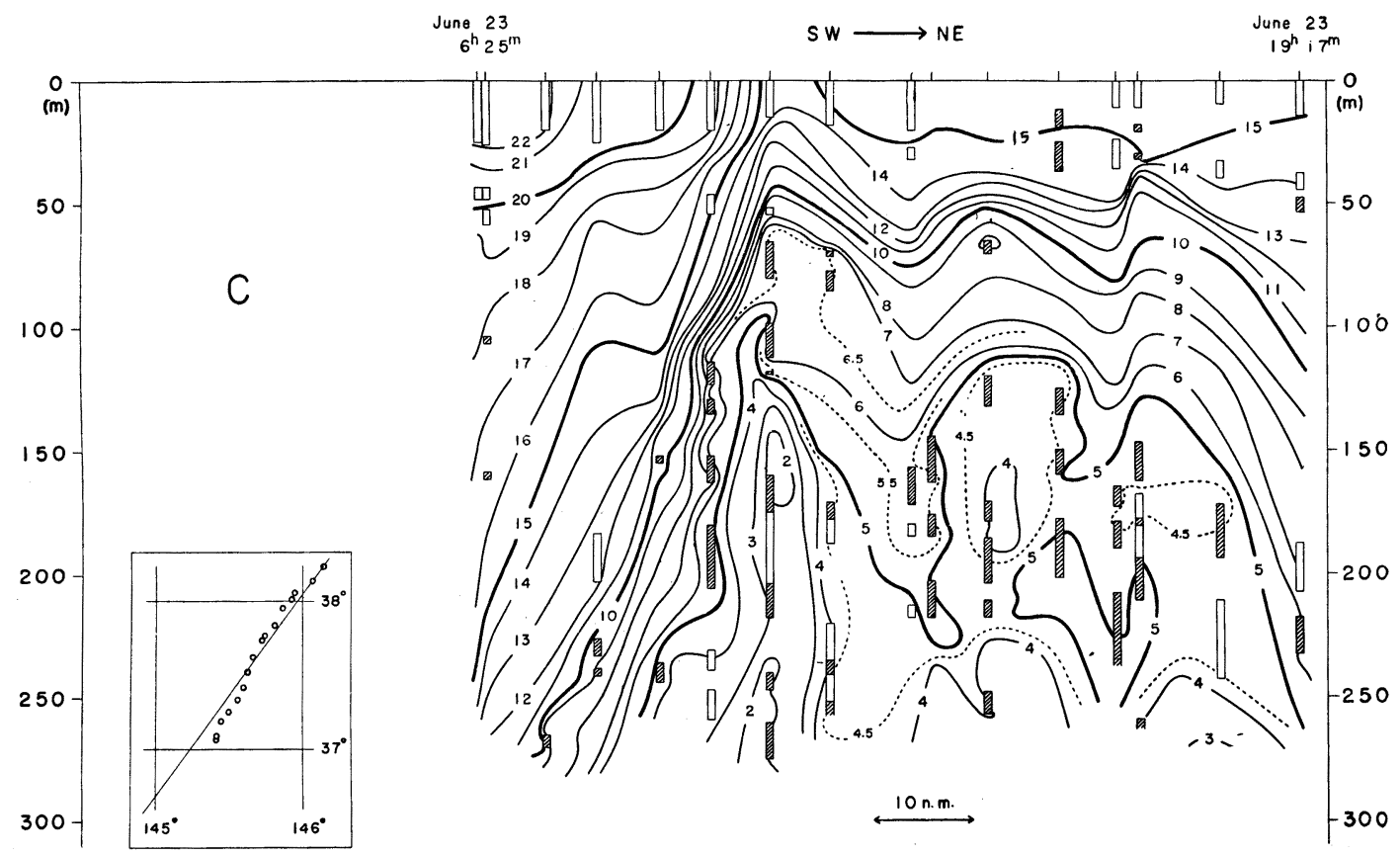

Fig. 4c. Temperature cross-section across the Kuroshio front. 


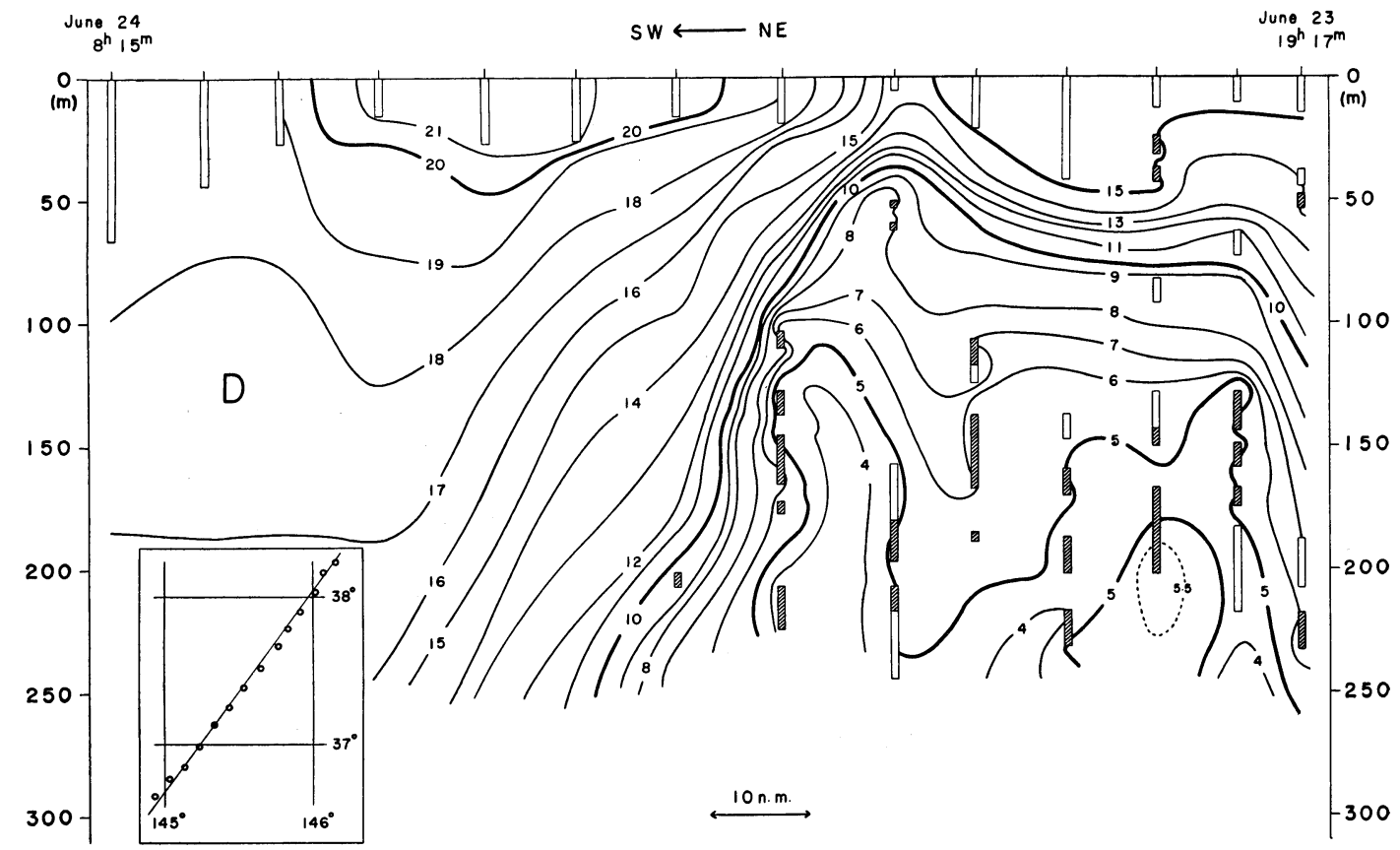

Fig. 4d. Temperature cross-section across the Kuroshio front.

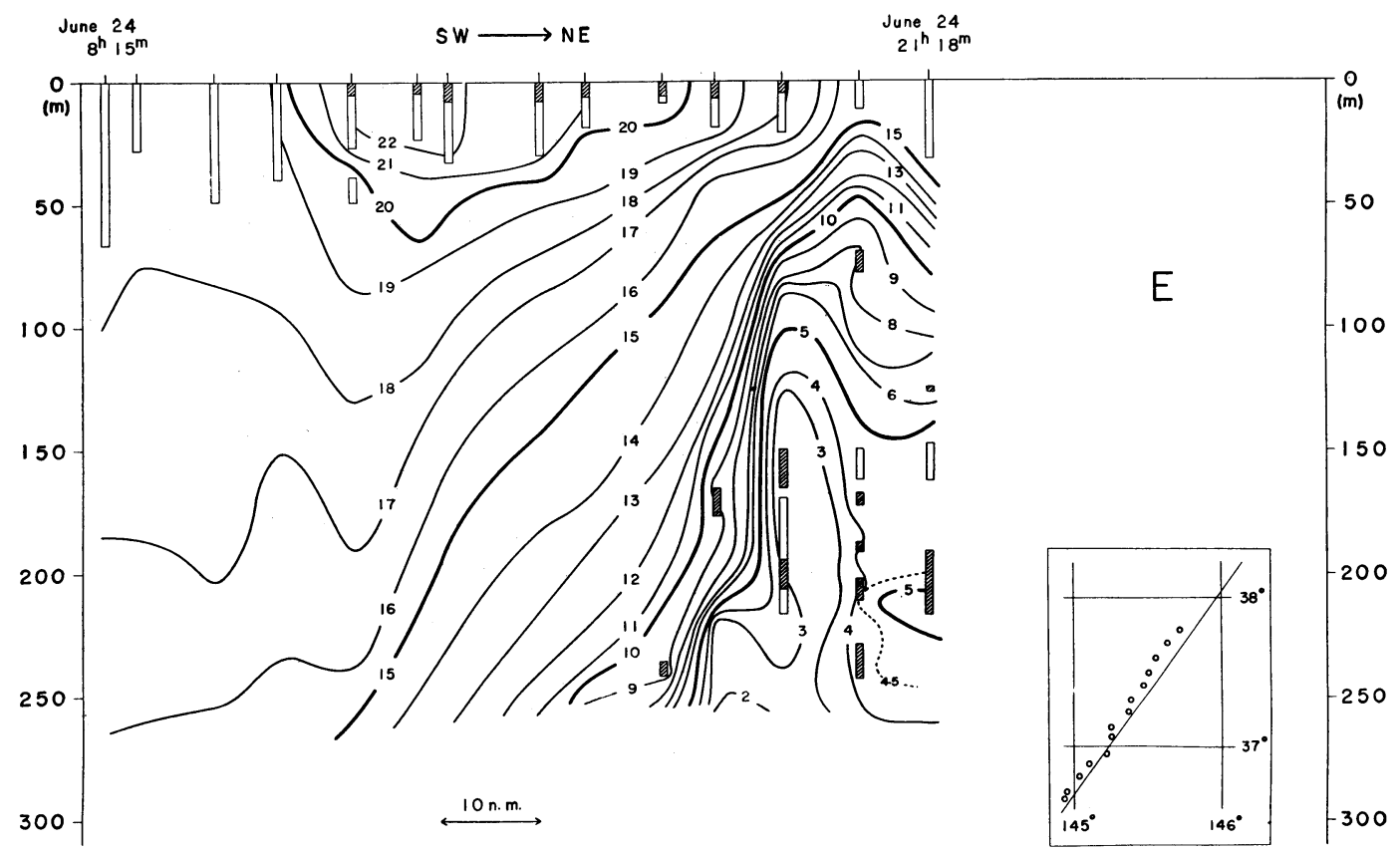

Fig. 4e. Temperature cross-section across the Kuroshio front. 
(MASUZAWA, 1958). As a part of this project, the Ryofu-maru of Japan Meteorological Agency repeatedly occupied a line perpendicular to the Kuroshio front and fairly dense BT observations were done from June 22 to June 24 . Five oross-sections of the temperature field are drawn from the obtained BT traces and shown in Fig. 4a through Fig. 4e. In these figures, positions of temperature inversion layers and homogeneous temperature layers are indicated by shaded rectangles and white rectangles, respectively. Actual locations of the BT measurement with respect to the reference line are shown in each attached figure. In the drawing of Fig. $4 \mathrm{a} \sim \mathrm{e}$, each station is projected to the reference line and observed temperature profile is assumed to be correct on the reference line.

The time needed to complete one section corresponds to the time between successive sectional observations. In view of the fact that the temperature field varys considerably from section to section, the temperature field of each section cannot be assumed simultaneous. In other words, the detailed structure in Fig. 4 gives a certain representation about a mixture of the spatial and temporal variations of the temperature field. Also, the change between the successive temperature sections does not necessarily indicate the temporal change of the temperature field, because it suffers from the spatial variation of the temperature field due to the deviation of each BT station from the reference line. Moreover, because of a strong current flowing across the section, some parts of the variation must be attributed to the advective water motion.

Now disregarding these complications for a while, we can say by examing Fig. 4a e that the temperature cross-section becomes more complicated as the interval of the observation becomes smaller. For the most part, we cannot find any correlation between inversions observed at successive stations. It seems that the interval of observation (roughly from 5 to 10 nautical miles) is too large to investigate small scale phenomena such as temperature inversions. This fact supports the conclusion of the former section that the horizontal scale of the "small scale" temperature inversion is of the order of 10 nautical miles. It is also difficult to find the relation between inversions observed in the successive sections, averaged time difference of which is about 12 hours. This fact suggests that the durability of the "small scale" temperature inversion is less than 12 hours, though some part of the change must be attributed to spatial structure of the temperature field.

One exceptional case in which we can find the correlation both between the successive stations and between the successive sections is the inversion which is accompanied with the warm water mass appearing at the depth between 200 and $250 \mathrm{~m}$ in the region north of the cold water belt. The temperature of this warm water mass exceeds $5^{\circ} \mathrm{C}$. The $5^{\circ} \mathrm{C}$ isotherm surrounding the warm water is clearly isolated from the upper $5^{\circ} \mathrm{C}$ isotherm in every section. So it can be easily identified despite its shape changing considerably from section to section. The horizontal scale of the warm water mass is maximum in Section B and about 30 nautical miles. The warm water mass can be seen in all sections and so its durability is longer than 2 days*. Even in this case, the spatial and temporal intervals of the observation were too large to investigate the structure of the temperature inversions because of the variability of the shape of inversion layers.

As mentioned above, the observation was not sufficiently detailed to trace the change of individual inversion layer; however, the statistical characteristics of the inversion layers can be deduced from Figs. 4a e. The temperature structure is very simple to the south of the Kuroshio front**, where the temperature inversion scarcely appears. An example of the horizontal distribution of occurrence of the shallow temperature inversions is shown in Fig.

* If the shape of the inversion layer does not change in time, this gives a measure of the horizontal scale in the direction perpendicular to the cross-section. The scale is more than 25 nautical miles if the current velocity is assumed about 0.5 knots.

** Here, the term "Kuroshio front" is referred to the portion where the horizontal temperature gradient shows the maximum value in sections. 


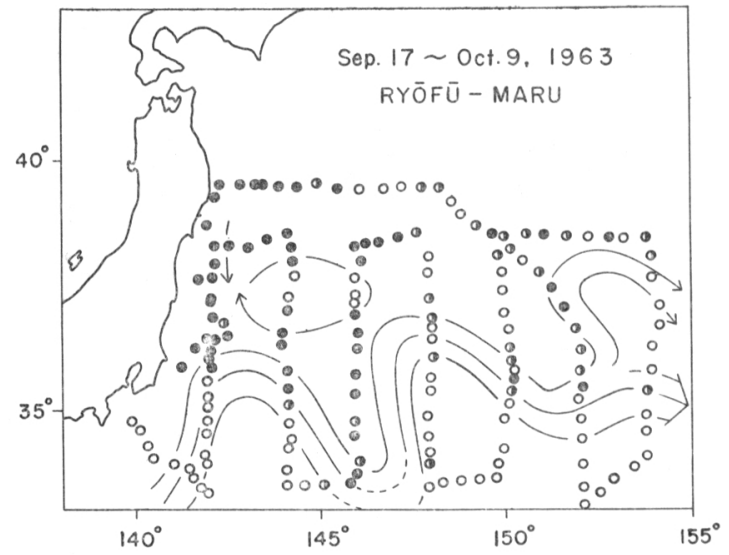

Fig. 5. An example of the horizontal distribution of occurrence of temperature inversion layers. - sum of the inversion temperature differences larger than $0.6^{\circ} \mathrm{C}$, : sum of the inversion temperature differences larger than $0.1^{\circ} \mathrm{C}$ and smaller than $0.5^{\circ} \mathrm{C}$, and $\bigcirc$ : no temperature inversion is found.

5. It is also clear from this figure that the path of the Kuroshio gives the southern boundary of the area where the temperature inversions are abundant.

The prominent cold water can be seen just to the north of the Kuroshio front in all sections. All isotherms are raised in this region, and the width of this cold water belt is about 10 nautical miles. The temperature structure north of the cold water belt is very complicated and the cold water mass and warm water mass appears alternately. The above-mentioned warm water mass is found in this region. Such a basic temperature structure is unchanged in all sections and is reflected in the occurrence of the temperature inversions. In Fig. 6, the variation of the sum of inversion temperature differences $\Sigma \Delta T$ are shown for each section. In this figure, reticulated portion indicates roughly the position of the Kuroshio front and dotted portion the position of the cold water belt. The temperature inversions are observed at every stations in and north of the Kuroshio front. The maximum of $\Sigma \Delta T$ appears in the region of the cold water belt for each sections. It is interesting that the strong temperature inversions are found in the place where isotherms are raised in temperature cross-section.

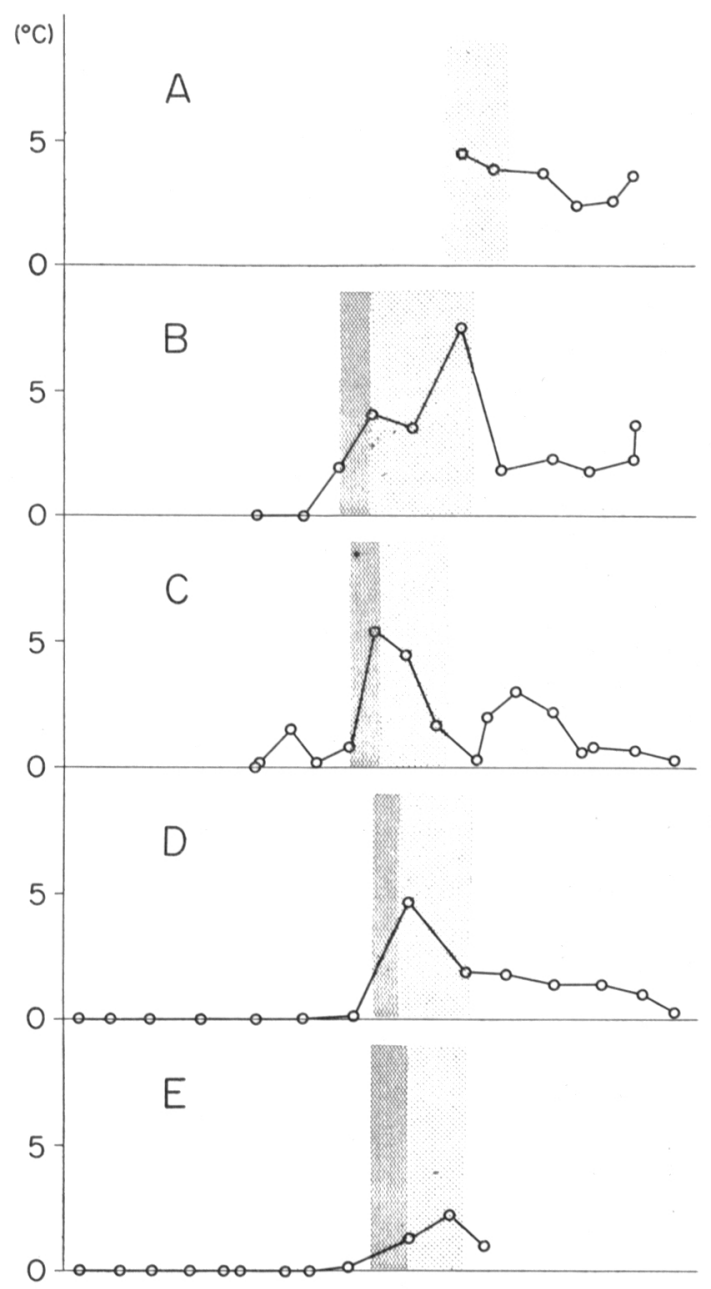

Fig. 6. The variations of the sum of the inversion temperature differences for each section. Reticulated portion indicates roughly the position of the Kuroshio front and dotted portion the position of the cold water belt.

MASUZAWA (1958) discussed the cold water belt along the northern boundary of the Kuroshio and concluded that this cold water belt was originated near Cape Kinkazan and carried to the region of interest at the rate of 20-30 nautical miles per day by advective motion along the northern edge of the Kuroshio. However, by considering that this cold water belt has such a narrow width and that it is accompanied with many temperature inversions, dissipation of the cold water belt by mixing must be considerable, so that vertical movement 
of the subsurface water seems to play some role both in maintenance of the cold water belt and in generation of the temperature inversion layers.

\section{Temporal scale of the temperature inversion layers}

In order to know the true durability of the inversion layers, we must make an observation moving with the inversion layer*, but it may not be practical at present to plan such an observation as we know very little about the characteristics of "small scale" inversion layers. Therefore, as a first step, it is desirable to investigate the temporal scale of the inversion layer observed at a fixed position. Unfortunately, the serial BT observations at a fixed position have been made on rare occasions. However, some examples can be shown below.

KURODA (1960) made a 48 hours serial BT

* Such an observation can be done only when the whole shape of the inversion layer can be traced in a short time. Use of thermistor chain will be advisable to this purpose. observation at interval of about 2 hours at a fixed position off the Sanriku Coast of Japan. $\mathrm{He}$ reported that a temperature inversion layer could be identified for the time longer than 12 hours, though its depth increased gradually from $60 \mathrm{~m}$ to $100 \mathrm{~m}$.

On a routine cruise of Ryofu-maru of Meteorological Agency, 8 BT observations were made at almost the same position $\left(40^{\circ} 23^{\prime} \mathrm{N}, 144^{\circ} 30^{\prime} \mathrm{E}\right)$ within 42 hours in September 1959. These 8 BT traces are shown in Fig. 7. So as to clearly the time change of temperature profiles, successive traces are shown in the same figure, and the whole $8 \mathrm{BT}$ traces are shown together in the last figure. It is not so easy to find the detailed correspondence between successive temperature profiles because the observational interval of about 6 hours is too large. However, some of the temperature inversions can be identified through two or three successive traces.

These examples support our estimation in the previous sections that the temporal scale of the small scale temperature inversion is of order of a day. This means that we must select the time interval of the observation to be of order of an
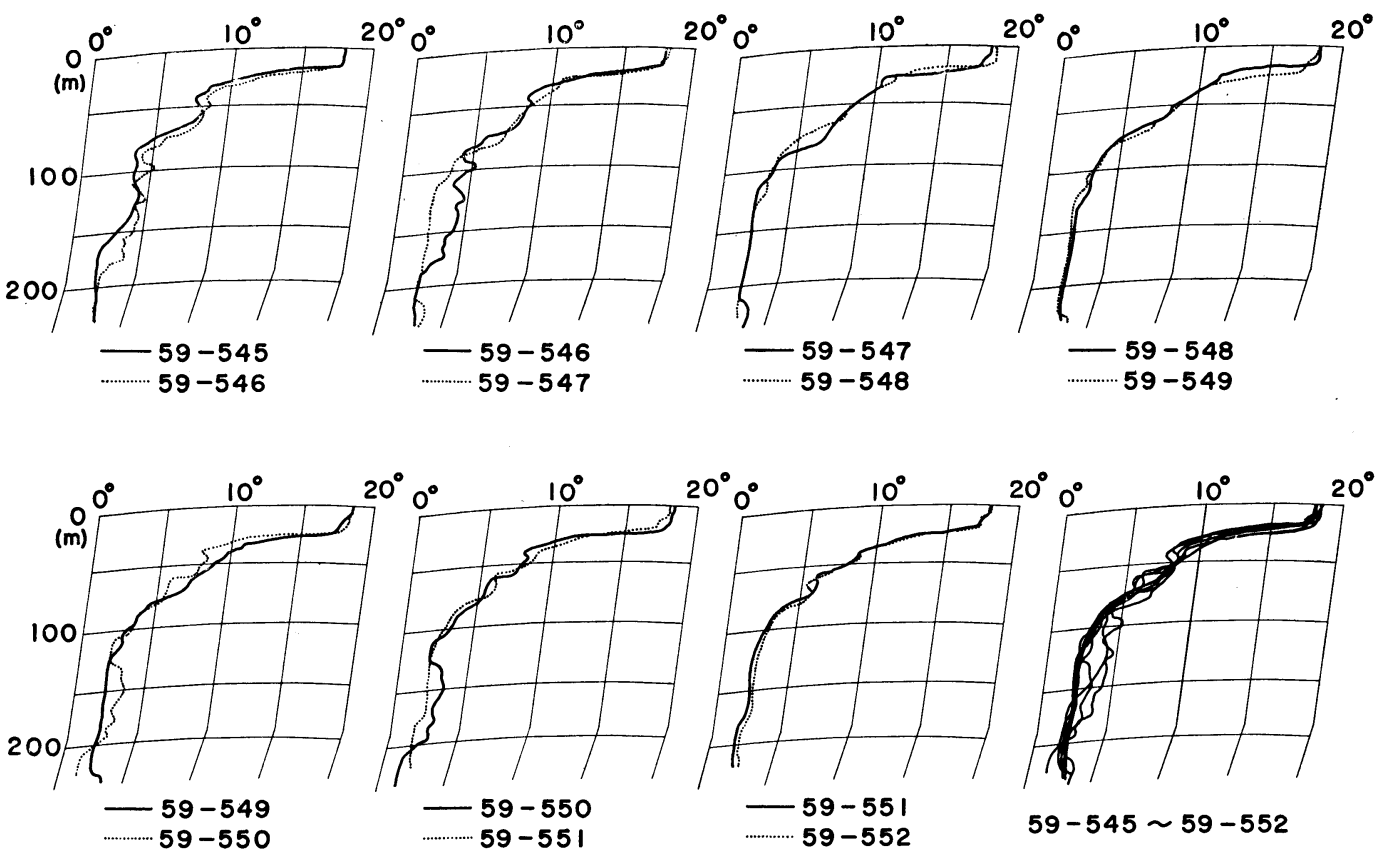

Fig. 7. BT traces which were taken at almost the same position $\left(40^{\circ} 23^{\prime} \mathrm{N}, 144^{\circ} 30^{\prime} \mathrm{E}\right)$ in September 1959. The time intervals between each successive measurements are about 6 hours. 
hour so as to know the detailed variation of inversion layers.

\section{Acknowledgments}

The author wishes to express his thanks to Professors Kozo YoshidA and Toshihiko TERAMOTO, University of Tokyo, for their encouragement and advices and Messrs. Akio MAEDA and Keiichi HASUNUMA, University of Tokyo, for their advices and discussions. He is much indebted to the chief of Oceanographic Division of the Japan Meteorological Agency for having kindly supplied the necessary data.

\section{References}

KAWAI, H. (1955): Notes on the inversion of the upper water temperature in the waters to the northeast of Japan in summer. Bull. Tohoku
Reg. Fish. Res. Lab., 6, 71-80.

KURODA, R. (1959): Notes on the phenomena of "inversion of water temperature" off the Sanriku Coast of Japan (I). Bull. Tohoku Reg. Fish. Res. Lab., 13, 1-12.

KuRODA, R. (1960): Notes on the phenomena of "inversion of water temperature" off the Sanriku Coast of Japan (II), Results from repeated observation in the fixed point. Bull. Tohoku Reg. Fish. Res. Lab., 16, 65-86.

MASUZAWA, J. (1958): A short period fluctuation of the Kuroshio east of Cape Kinkazan. Oceanographical Magazine, 10 (1), 1-8.

NAGATA, Y. (1967): Shallow temperature invesions at Ocean Station V. Jour. Oceanogr. Soc. Japan, 23 (4), 194-200.

RODEN, G. I. (1964): Shallow temperature inversion in the Pacific Ocean. Jour. Geophys. Res., 69 (14), 2899-2914.

\section{温度逆転層の構造について}

永田豊

要旨 比較的密な間隔で行なわれた $\mathrm{BT}$ 観測の資料をも とにして, 表層に現われる小規模な温度逆転層の構造を 論じた.

温度逆転は親潮と黒潮との間の混合域のように, 温度 分布が複雑な海域に多く現われ, 黒潮前線の南側にはあ まり現われない. 特に温度分布の鉛直断面をとった時 に等温線がもち上げられて, 上向きの移流が存在するか
のように見える場所では大きな温度逆転が見出された.

一般に, 小規模な温度逆転層の水平スケールは 10 浬 のオーダーである.したがって, 逆転層の構造を調べる ためには，比較的スケールの大きなものについても， 3 浬以下の間隔で観測を行なう必要がある. また, 逆転首 の形は 1 日のろちにかなり変化するので, 時間間隔も 1 時間のオーダーにとる必要がある. 